Journal of Engineering and Applied Sciences 14 (8): 2398-2408, 2019

ISSN: 1816-949X

(C) Medwell Journals, 2019

\title{
Success Factors for Physical Activity Among Children and Adolescents with Hearing Impairments
}

\author{
${ }^{1}$ Shokhan Omar Abdulrahman, ${ }^{1}$ Mohd Radzani Abdul Razak, ${ }^{1}$ Mohd Hanafi Mohd Yasin and \\ ${ }^{2}$ Lim Boon Hooi \\ ${ }^{1}$ Faculty of Education, Universiti Kabangsaan Malaysia, 43600 Bangi, Selangor, Malaysia \\ ${ }^{2}$ Sport Centre, University of Malaya, 50603 Kuala Lumpur, Malaysia
}

\begin{abstract}
It is universally known that physical activity can be beneficial for physical and mental health. Several studies have indicated that children with hearing impairments possess diminished motor ability and motor skills in comparison with normal hearing children which may lead to less Physical Activity (PA). Therefore, it is necessary to identify the needs and current levels of activity to assess the effectiveness of intervention programs in order to increase physical activity. The main purpose of this article is to identify the factors that could have an effect on Physical Activity (PA) among children and adolescents with Deafness/Hearing Impairments (D/HI). The method used was a review of current studies of physical activity in order to collect the factors that have impact on children and adolescents with D/HI. The result showed that social and environmental factors, physical fitness and psychological factors can lead to an increase in PA. In addition, the literature provided a few studies about physical activity specifically for those with D/HI. From this study, we can conclude that a combination of these factors has been rarely considered in the previous research. Therefore, there is a need to fill this gap in the literature in order to provide decision makers with in-depth understanding of the current needs of children and adolescents with $\mathrm{D} / \mathrm{HI}$ for the purpose of assessing their needs in different aspects.
\end{abstract}

Key words: Physical activity, children and adolescents, deafness, hearing impairments, physical fitness, social, psychological, environment

\section{INTRODUCTION}

According to WHO (2013) PA is any movement that involves energy consumption. Being physically active during childhood and adolescence is important for physical, mental and social well-being (Trinh, 2007). This is because development of physical activity behaviors is likely to persist into adulthood (Button, 2013). Activities like walking or cycling and also other activities of normal day-to-day living (e.g., shopping, cleaning, climbing stairs) have been recognized as effective ways for children and adolescents to engage in physical activity which is important for their health (WHO., 2014). The children and adolescents who engage in regular PA tend to carry over this active lifestyle into adulthood (Ellis et al., 2013). Consequently, more attention is being placed on understanding the environments and policies that support lifelong PA and active transportation (Sallis et al., 2006) (Table 1).

Regular PA has been indicated to benefit various body systems such as cardiovascular, respiratory,

\begin{tabular}{ll} 
Table 1: List of abbreviations & \\
\hline Abbreviations & Details \\
\hline PA & Physical Activity \\
PF & Physical Fitness \\
D/HI & Deafness/Hearing Impairments \\
MVPA & Moderate to Vigorous Physical Activity \\
\hline
\end{tabular}

musculoskeletal, nervous, endocrine and immune systems (Sampasa-Kanyinga et al., 2017). Therefore, PA is of importance in optimizing health and reducing the risk of obesity and other chronic diseases (Nicolas et al., 2015). PA has many associated health benefits: it decreases risk of obesity and independently decreases morbidity and mortality (Nicolas et al., 2015). It has been well documented that regular physical activity has important benefits for health (Xu et al., 2016).

Evidence also shows that physical activities are beneficial to health during childhood and adolescence. Recommendations for increased physical activities have been integrated with so many guidelines including those from the world health organization with 'move for health program' (Bult et al., 2011). However, despite all these guidelines, there are still many people reported to be

Corresponding Author: Shokhan Omar Abdulrahman, Faculty of Education, Universiti Kabangsaan Malaysia, 43600 Bangi, Selangor, Malaysia 
physically inactive (Artero et al., 2010). A study has reported that children aged 6-11 years with hearing impairment have lower levels of PA participation compared to their normal hearing peers (Sue, 2015).

Unfortunately, children with $\mathrm{D} / \mathrm{HI}$ may have poorer health-related fitness than their normal hearing peers and this could place them at risk for secondary health problems (Hartman et al., 2007). In the developing countries the children face many challenges in their health and education (Ahmed et al., 2016; Kadhum and Hasan, 2017). A study was carried out among 61 hearingimpaired students from a special school for the deaf in Malaysia. The study showed that poor physical fitness among children with $\mathrm{D} / \mathrm{HI}$ has an association with a lifestyle that lacks active physical activity. Besides that, lack of motivation can also affect the PA as well as physical fitness (Abdullah et al., 2014). Children with $\mathrm{D} / \mathrm{HI}$ may be short of minimal physical fitness and motor skills which may in turn negatively impact PA engagement (Martin et al., 2013).

Some studies have consistently demonstrated that parents' attitudes toward PA and fitness can have very significant influence on the PA habits of $\mathrm{D} / \mathrm{HI}$ children. Martin et al. (2013) and Ellis et al. (2013). A study among 128 deaf children in grades one to four with parents who were involved found a significant positive relationship between parent's attitudes toward physical fitness and sport participation and their children's PA and fitness levels as well as between participation in deaf sport by deaf parents and children's PA levels (Martin et al., 2013). Another study was conducted among 64 children from two large cities, one in the USA and the other in the Czech Republic. Participants were male and female youth aged 14 years. The study found that $\mathrm{D} / \mathrm{HI}$ students who did not receive strong friend support had low self-efficacy and did not enjoy physical education classes (Martin et al., 2013). Cozett (2014) studied 600 students aged 11-13 years from two schools in South Africa and found that those who had high self-efficacy reported a high level of PA participation in contrast to those who had low levels of confidence and self-efficacy (Cozett, 2014). Furthermore, during adolescence, self-efficacy that promote lifelong patterns of PA should be emphasized (Cozett, 2014).

The built environment of the school can influence the PA levels of students. The school's built environment consists of the facilities that can encourage PA such as gymnasia, fields and fitness rooms (Button, 2013). Research among 17,917 students in grades 6-10, from 316 schools who participated in the 2009 Canadian Health
Behavior in school-aged children, found a positive association between the schools' built environments and school time MVPA (Button, 2013).

Children and adolescents with D/HI have little experience with environmental constructs to predict PA because they spend less time outside the home. Parental concerns about their safety or the fact that they have few friends who know sign language could significantly reduce their experience with environmental constructs (Martin et al., 2013). Barriers of the living environment for people with $\mathrm{D} / \mathrm{HI}$ can reduce their participation in daily PA such us to walk or jog in the neighborhood due to road traffic, sidewalks and the like (Kurkova, 2016). Busy urban areas with the presence of bikes and cars represent a hazardous environment for $\mathrm{D} / \mathrm{HI}$ people as they are unable to rely on their hearing but to depend on sight. Therefore such people are in great need of play spaces without bikes and cars (Martin et al., 2013). There is increasingly more evidence of certain built environments, especially outdoor spaces like parks and playgrounds and their association with higher PA levels (Nicolas et al., 2015).

Furthermore, D/HI people also face challenges in psychosocial adjustment and social integration in comparison with nondisabled populations or individuals with other disabilities. In particular, besides their inability to hear, $\mathrm{D} / \mathrm{HI}$ children also display a limited vocabulary capacity which makes it difficult for them to communicate orally In turn, their self-efficacy is affected, when they participate in physical activity (Sue, 2015). Inactivity among $\mathrm{D} / \mathrm{HI}$ children has been associated with a range of factors (Ellis et al., 2013). There have been relatively few studies on PA among D/HI people and as such there is inadequate understanding of their PA requirements.

\section{MATERIALS AND METHODS}

A literature survey was carried out to collect the related information regarding factors that have been used in the physical activity context.

Different studies have investigated some antecedents facing the children's physical activity. The collected factors have been categorized in different domains according to previous studies.

Physical fitness: Physical fitness is defined as the level of ability to engage in PA that combines most of the bodily functions with the various components grouped into those associated with health and those associated with athletic skill (Bianco et al., 2015). Five physical fitness components have been determined: 
Body composition: Body composition is recognized as one of the main health-related elements of Physical Fitness (PF) that is impacted by body weight and connected to muscles, fat, bone and other important body tissues. This element of a larger reduces the fat which is measured as a body fat percentage and total body weight in kilograms (Sarah, 2011).

Body fat percentage as 6-10 and 12-15 in boys and girls, respectively could have negative effects which could be predictive of the incidence of disease, eating disorders or malnourishment and also irregular menstrual cycles among girls. According to Toriola (2013), females are more likely to have elevated body fat percentage compared to males. Children and adolescents with body fat percentage beyond 25 and $30 \%$ for boys and girls, respectively are in greater danger of developing various types of hypokinetic diseases (Toriola, 2013). Additionally, the sex differences in body fat could be physiologically metabolically or socially induced while excess body fat during childhood could negatively affect PA. Hence, the body composition within the standard value can be assessed to improve the PA level among $\mathrm{D} / \mathrm{HI}$ children (Wilson et al., 2011; Sarah, 2011; McNamee et al., 2016).

Aerobic capacity: Aerobic capacity is the ability of circulatory and respiratory systems to provide fuel and oxygen to active muscles when engaged in PA and to avoid muscle fatigue (Jiying, 2013). Elevated levels of aerobic capacity have been known to reduce mortality in adults and minimize the risk of cardiovascular disease in youth and some evidence has suggested that fitness continues from childhood into adulthood (Larouche $e t$ al., 2014).

Aerobic performance is an important health marker from childhood and adolescence. It is defined as the ability to feed oxygen to muscles for generating energy during physical exercises.

Therefore, it depends on pulmonary, cardiovascular and hematological components of oxygen delivery and oxidative mechanisms of the exercising muscle. On the other hand, low aerobic performance is associated with low capacity to release energy through oxidation processes for muscular work support, causing premature fatigue and difficulty in performing daily or physical activities (Sarah, 2011). Most studies have found a positive association between aerobic performance and PA level (Vancampfort et al., 2016; Abdullah et al., 2014).

Muscular strength: Muscular strength refers to "the ability of muscle to exert force. Strong muscles are required for normal $\mathrm{PA}$ and to be able to live a happy life. Strength is definitely essential for fitness and wellness and is very important for ideal performance in day-to-day activities-sitting, walking, running, lifting and moving objects and performing domestic chores or even for recreation purposes (Vancampfort et al., 2016). Muscular strength is associated with a healthier cardiovascular profile already in childhood and adolescence (Leily et al., 2014).

Currently, it is recommended that young people should spend no less than an hour on moderate-tovigorous physical activity daily or at least on most of the week. It is suggested that at least twice a week should be devoted to activities to enhance bone health and muscle strength (Larouche et al., 2014). This is because a high level of muscular strength may allow an individual to engage in more recreational activities (Martinez-Vizcaino and Sanchez-Lopez, 2008).

Many studies have reported that less muscular strength is associated with less PA (McNamee et al., 2016; Vancampfort et al., 2016). Another study among 89 middle school children aged 11-15 years showed PA was significantly related to muscular strength (Leily et al., 2014).

Muscular endurance: This refers to the ability of a person to do repeated movements for long periods without excessive fatigue (Echeverria, 2014). Muscular endurance is the main aspect of muscular fitness. Optimal levels of muscular endurance may help improve motor development and PA level (McNamee et al., 2016).

Ideal muscular endurance must be maintained to have better posture, less back problems and enhanced tolerance to muscle fatigue compared to others who lack muscular endurance (McNamee et al., 2016).

Muscular endurance is also important in our daily activities such as walking, working and playing which involve muscular contraction and relaxation and people who possess good muscular endurance are said to have a greater working capacity (Toriola, 2013). Several studies have found that less cardiovascular endurance and muscular fitness are associated with less physical activity (Vancampfort et al., 2016).

Flexibility: Flexibility is one of the most important types of PA and related to health fitness (McNamee et al., 2016). The benefits are derived from all activities that involve bending, lunging, twisting, reaching and stretching. Everyone needs a certain level of flexibility to be efficient and effective in daily life (Martin et al., 2011a, b). 
Flexibility is related to the physical characteristics of skeletal muscle, tendons and fibrous tissue and also to neuromuscular activation of related muscle groups. Children's flexibility stays constant from age 5-8 years whereas significant decline of flexibility is at $12-13$ years and with advancing age (Ellis et al., 2013). The flexibility in females is higher than in males among children in primary school (Leily et al., 2014; Ellis et al., 2013).

Social domain: Social domain is a motivation to increase PA level among D/HI children and adolescents (Cozett, 2014; Richard, 2015). Social domain of physical activity includes:

Parental support: A number of studies have demonstrated that parents play a key role in the level of their children's' PA (Baskin et al., 2015). This is because parents can make significant contributions to the variables that strengthen children's behavior. Much research has been done to study parental influence and results have consistently found that it plays a role in influencing children's activity patterns (Cozett, 2014; Welk et al., 2003).

While parent can have an important impact on the PA levels of their children and adolescents, they are advised to limit the use of electronic media by school-aged children (Huang et al., 2011) and instead motivate them to be more physically active. Furthermore, parents can help their children significantly reduce time spent in sedentary behaviors by making available PA equipment and using commercial facilities which would offer children more options to be physically active (Garcia et al., 2016).

A study has revealed that children and adolescents without parental motivation were very much more likely to see more obstacles to PA compared to those who were encouraged by parents. The study by Jiying (2013) showed the relationship between parent support and PA and the results indicated that those with low levels of parental support had a $23-55 \%$ greater tendency to be inadequately active for health benefits in comparison with those whose parents provided full support (Jiying, 2013).

Parental role modeling: Is a factor of motivation to increase PA levels among children and adolescents. Self-reported by parents it have been found to be a significant predictor of adolescents more frequent engagement in PA. Parental role modeling implies efforts by parents to create a model of PA lifestyle for their children (Richard, 2015).

Based on Social Cognitive Theory (SCT), parental role modeling should influence children and adolescent's
PA because this variable offers resources that could enhance a child's confidence in his/her ability to behave in a certain way (Martin et al., 2013).

Previous research has demonstrated that children's PA is affected by their parent's attitudes toward things like the benefits of PA for their children, successful expectancies and objectives and views of their children's PA performance (Garcia et al., 2016).

Peer support: Is an important determinant of PA in children and adolescents. The introduction of sports may come at an early age and be influenced by peers. Peer support can provide additional incentive and motivation to engage in PA (Liang et al., 2014). Among adolescents, interacting with friends can lead to several possible outcomes such as cognitive, social, psychosocial and emotional development and behavior of PA (Martin et al., 2013).

Garcia et al. (2016) is a research made use of focus groups to investigate social impacts of PA among children aged 10-11 years and found that friendship groups were significantly influential on where they exercises and what PA they were engaged by Garcia et al. (2016). Support from friends is consistently and positively associated with PA (Hinckson et al., 2014). A study among 600 students aged 11-13 years, found that peer support was the highest-ranked factor in relation to MVPA among children and adolescents (Baskin et al., 2015).

This concurs with earlier studies which suggested that perceived support from peers had a significant positive direct influence on PA. For instance, in a recent study of a group of rural high school girls, their peers were found to directly affect their perception of PA (Huang et al., 2011).

Environmental domain: The environmental domain plays an important role in modulating the levels of PA. Physical environment aspects related to engagement in PA are strong and individuals are motivated to be physically active. Environmental domain of physical activity, including:

Equipment access: A positive association between availability of equipment access and adolescent MVPA has been quite consistently reported (Baskin et al., 2015). Recently, several studies have reported that children and adolescents who reside in the vicinity of PA facilities predictably show elevated levels of PA (Cozett, 2014). Adolescents living within a 0.75 mile street network buffer of one or more commercial PA facilities were involved in more Vigorous Physical Activities (VPAs) (Wilson et al., 
2011). Commercial PA facilities offer children the opportunity to engage in the recommended $60 \mathrm{~min}$ of MVPA that children and adolescents should accumulate each day (Baskin et al., 2015).

Home equipment, whether placed in the house or outside (in the backyard) that facilitate or discourage PA, could have significance influence on PA and sedentary time. It can be expected that the existence of opportunities to be active (such as sport or recreation equipment in a home) or sedentary (such as the number of television sets or other media equipment in a home) would affect PA levels. More chances of being active within the school setting might enhance children's and adolescents' PA levels, even in schools with limited sports facilities (Cozett, 2014).

Park facilities for PA offer an significant resource that may positively affect PA engagement levels among children and adolescents (Spratt-O'Shea, 2014). Park features (i.e., type of activity area and the adequacy of equipment and supplies) have a positive association with PA in the park (West et al., 2012).

Neighborhood safety: This has a crucial role to play in how parents and children respond to the environment. Despite children having access to PA equipment or supplies, it is crucial that there are no concerns about the safety of the environment which could prevent children from utilizing these facilities (Xu et al., 2016).

It should be noted that children's views about their neighborhood can alter over time from less positive to positive for PA, probably due to growing awareness of the benefits and nature of their neighborhood. For instance, it is not surprising that over time, their neighborhood is viewed as less hazardous from traffic in adolescence in comparison with their childhood. This is because as adolescents individuals have learned motor skills and traffic awareness skills to be able to walk and cycle surely in the vicinity of their neighborhood (Xu et al., 2016).

However, barriers including crime, traffic speed, dogs have an inverse association. There is growing evidence on the link between certain built environments, especially outdoor safe spaces like parks and playgrounds and elevated PA levels (Hinckson et al., 2014).

Place for walking and cycling: At neighborhood level, among adolescents aged 11-17 years, the lack of sidewalks, proper pathways and unsafe spaces for walking and biking in the neighborhood and safety factors are positively associated with $\mathrm{PA}$, defined as $<150 \mathrm{~min} /$ week of moderate PA or $<60 \mathrm{~min} /$ week of vigorous PA. Consistent with Western studies, this suggests that positive places for walking and cycling may facilitate the PA of children and adolescents with $\mathrm{D} / \mathrm{H}$ in Asian countries (Ding et al., 2011).

A search of the transportation research and urban planning literature reveals easy pedestrian access to nearby destinations has a relationship with active transportation choices, especially walking. Therefore, the choice of neighborhood could be for the purpose of moderating the relationship between walkability and walking behavior (Nicolas et al., 2015).

Poor housing is an important cause of a large number of health problems which have challenged public health authorities. Beyond the condition of the actual housing unit, the physical and social environment of the home impacts the health and health behavior of residents. Even though neighborhood-level influences on health have been well documented in recent decades, the significance of the residential environment in determining health and health behavior is still a novel research niche. In the past 10 years, the relationship between home environment and health behavior has garnered much interest (Sarah, 2011).

Access to services: The accessibility of services such as shops, public transportation, neighborhood grocery store, etc., dramatically affects individual to be more active. Walking to shops and walking as a form of exercise are significant contributions to adolescent's PA (Nicolas et al., 2015).

Neighborhood destinations, access to parks and living near green spaces are positively associated with MVPA. People of higher socio-economic status are likely to be more active in their leisure time but walking for transportation appears to be more significant among those of the lower socio-economic class who may not have easy access to their own transport and who use transit more frequently (Trinh, 2007).

Psychological domain: Psychology plays an important role in children and adolescents with $\mathrm{D} / \mathrm{HI}$ in their $\mathrm{PA}$ behaviors. Furthermore, promoting PA increases the well being and lowers mental health issues among children and adolescents.

Self-efficacy: According to Social Cognitive Theory (SCT) by Bandura, self-efficacy is a central influence on exercise behavior (Garcia et al., 2016). Nevertheless, the decline in PA is inversely related to self-efficacy to overcome barriers to PA and perceived support from peer sand family. Self-efficacy in PA refers to individual's beliefs about personal capabilities to engage in PA (Xu et al., 2016). Self-efficacy has been known to be an 
important predictor of $\mathrm{PA}$ among children and adolescents (Martin et al., 2011a, b). There is consistent and strong evidence of the positive correlation between self-efficacy and PA.

Dzewaltowski and colleagues revealed that children with greater levels of after-school PA had elevated PA self-efficacy compared to those with lower levels of PA. Research on adolescents has found that PA self-efficacy has a positive correlation with PA levels and the differences in PA in relation to sex were explained by the differences in self-efficacy between males and females (Huang et al., 2011). In a study of 72 adolescents revealed that only self-efficacy contributed significantly and uniquely to objective PA levels in comparison with other social cognitive variables like intention and perceived behavioral control. A study of 206 African American school-aged children discovered that a higher level of PA self-efficacy has a significant correlation with enhanced PA.
To reduce barriers to PA, there must be increase in self-efficacy and belief in PA outcome and the strengthening of social support in order to help adolescents to be healthier and more physically active (Campbell, 2012).

\section{RESULTS AND DISCUSSION}

Based on our analysis of relevant studies, critical success factors for physical activity were identified. These factors are considered important due to the considerable value if physical activity among children and adolescents with D/HI. Table 2 illustrates the deduced factors that have been collected based on a review of the literature. The classification of these factors is based on a certain domain for each factor. Special needs children and $\mathrm{D} / \mathrm{HI}$ adolescents normally exhibit lower physical fitness compared to their hearing peers and places them at risk for secondary health problems. In the physical

Table 2: The resources of factors used based on literature

\begin{tabular}{|c|c|c|c|c|c|c|c|c|c|c|c|c|c|}
\hline \multirow[b]{2}{*}{ Sources } & \multirow[b]{2}{*}{$\begin{array}{l}\text { Phycology } \\
\text { Self-efficacy }\end{array}$} & \multicolumn{3}{|l|}{ Social } & \multicolumn{4}{|c|}{ Environments } & \multicolumn{4}{|c|}{ Physical fitness } & \multirow[b]{2}{*}{ Flexibility } \\
\hline & & $\begin{array}{l}\text { Parental } \\
\text { support }\end{array}$ & $\begin{array}{l}\text { Parental } \\
\text { role } \\
\text { modeling }\end{array}$ & $\begin{array}{l}\text { Peer } \\
\text { influence }\end{array}$ & $\begin{array}{l}\text { Equipment } \\
\text { access }\end{array}$ & $\begin{array}{l}\text { Neighborhood } \\
\text { safety }\end{array}$ & $\begin{array}{l}\text { Place for } \\
\text { walking and } \\
\text { cycling }\end{array}$ & $\begin{array}{l}\text { Access } \\
\text { to services }\end{array}$ & $\begin{array}{l}\text { Body } \\
\text { composition }\end{array}$ & $\begin{array}{l}\text { Aerobic } \\
\text { capacity }\end{array}$ & $\begin{array}{l}\text { Muscular } \\
\text { strength }\end{array}$ & $\begin{array}{l}\text { Muscular } \\
\text { endurance }\end{array}$ & \\
\hline $\begin{array}{l}\text { Stewart et al. } \\
\text { (2017) }\end{array}$ & & & & & & & & & $\mathrm{x}$ & & & & \\
\hline $\begin{array}{l}\text { Sampasa- } \\
\text { Kanyinga et al. }\end{array}$ & 2017) & & & & & & & & $\mathrm{x}$ & & & & \\
\hline $\begin{array}{l}\text { Vancampfort } \\
\text { et al. 2016) }\end{array}$ & & & & & & & & & $\mathrm{x}$ & $\mathrm{x}$ & $\mathrm{x}$ & $\mathrm{x}$ & $\mathrm{x}$ \\
\hline $\begin{array}{l}\text { (McNamee et al. } \\
\text { (2016) }\end{array}$ & & & & & & & & & $\mathrm{x}$ & $\mathrm{x}$ & $\mathrm{x}$ & $\mathrm{x}$ & $\mathrm{x}$ \\
\hline $\mathrm{Xu}$ et al. (2016) & $\mathrm{x}$ & & & & & $\mathrm{x}$ & & & & & & & \\
\hline $\begin{array}{l}\text { Garcia et al. } \\
(2016)\end{array}$ & $\mathrm{x}$ & $\mathrm{x}$ & & $\mathrm{x}$ & & & & & & & & & \\
\hline Richard (2015) & & $\mathrm{x}$ & $\mathrm{x}$ & & & & $\mathrm{x}$ & & & & & & \\
\hline $\begin{array}{l}\text { Nicol as } \\
\text { et al. }(2015)\end{array}$ & & & & & & & $\mathrm{x}$ & $\mathrm{x}$ & $\mathrm{x}$ & & & & \\
\hline $\begin{array}{l}\text { Baskin et al. } \\
\text { 2015) }\end{array}$ & & $\mathrm{x}$ & & $\mathrm{x}$ & $\mathrm{x}$ & & & & & & & & \\
\hline Cozett (2014) & $\mathrm{x}$ & $\mathrm{x}$ & $\mathrm{x}$ & $\mathrm{x}$ & $\mathrm{x}$ & $\mathrm{x}$ & & & & & & & \\
\hline $\begin{array}{l}\text { Sebire in } \\
2014\end{array}$ & $\mathrm{x}$ & $\mathrm{x}$ & $\mathrm{x}$ & & & & & & $\mathrm{x}$ & & & & \\
\hline $\begin{array}{l}\text { Liang et al. } \\
(2014)\end{array}$ & $\mathrm{x}$ & $\mathrm{x}$ & & $\mathrm{x}$ & & & & & & & & & \\
\hline $\begin{array}{l}\text { Hinckson et al. } \\
\text { (2014) }\end{array}$ & $\mathrm{x}$ & $\mathrm{x}$ & & $\mathrm{x}$ & & $\mathrm{x}$ & $\mathrm{x}$ & & $\mathrm{x}$ & & & & \\
\hline $\begin{array}{l}\text { Larouche et al. } \\
\text { (2014) }\end{array}$ & & & & & & & & & $\mathrm{x}$ & $\mathrm{x}$ & & & \\
\hline Jiying (2013) & $\mathrm{x}$ & $\mathrm{x}$ & $\mathrm{x}$ & & $\mathrm{x}$ & $\mathrm{x}$ & & & $\mathrm{x}$ & & & & \\
\hline $\begin{array}{l}\text { Campbell } \\
(2012)\end{array}$ & $\mathrm{x}$ & & & & & & & & & & & & \\
\hline $\begin{array}{l}\text { West et al. } \\
\text { (2012) }\end{array}$ & & & & & $\mathrm{x}$ & & & & $\mathrm{x}$ & & & & \\
\hline Sarah (2011) & & & & & & & $\mathrm{x}$ & $\mathrm{x}$ & $\mathrm{x}$ & $\mathrm{x}$ & & & \\
\hline $\begin{array}{l}\text { Huang } \text { et al. } \\
\text { (2011) }\end{array}$ & $\mathrm{x}$ & $\mathrm{x}$ & & $\mathrm{x}$ & & $\mathrm{x}$ & & & & $\mathrm{x}$ & & & \\
\hline $\begin{array}{l}\text { Farias-Junior } \\
\text { et al. (2011) }\end{array}$ & & & & & & & $\mathrm{x}$ & & & & & & \\
\hline $\begin{array}{l}\text { Wilson } e t \text { al. } \\
\text { (2011) }\end{array}$ & & $\mathrm{x}$ & & & $\mathrm{x}$ & $\mathrm{x}$ & & & $\mathrm{x}$ & & & & \\
\hline
\end{tabular}




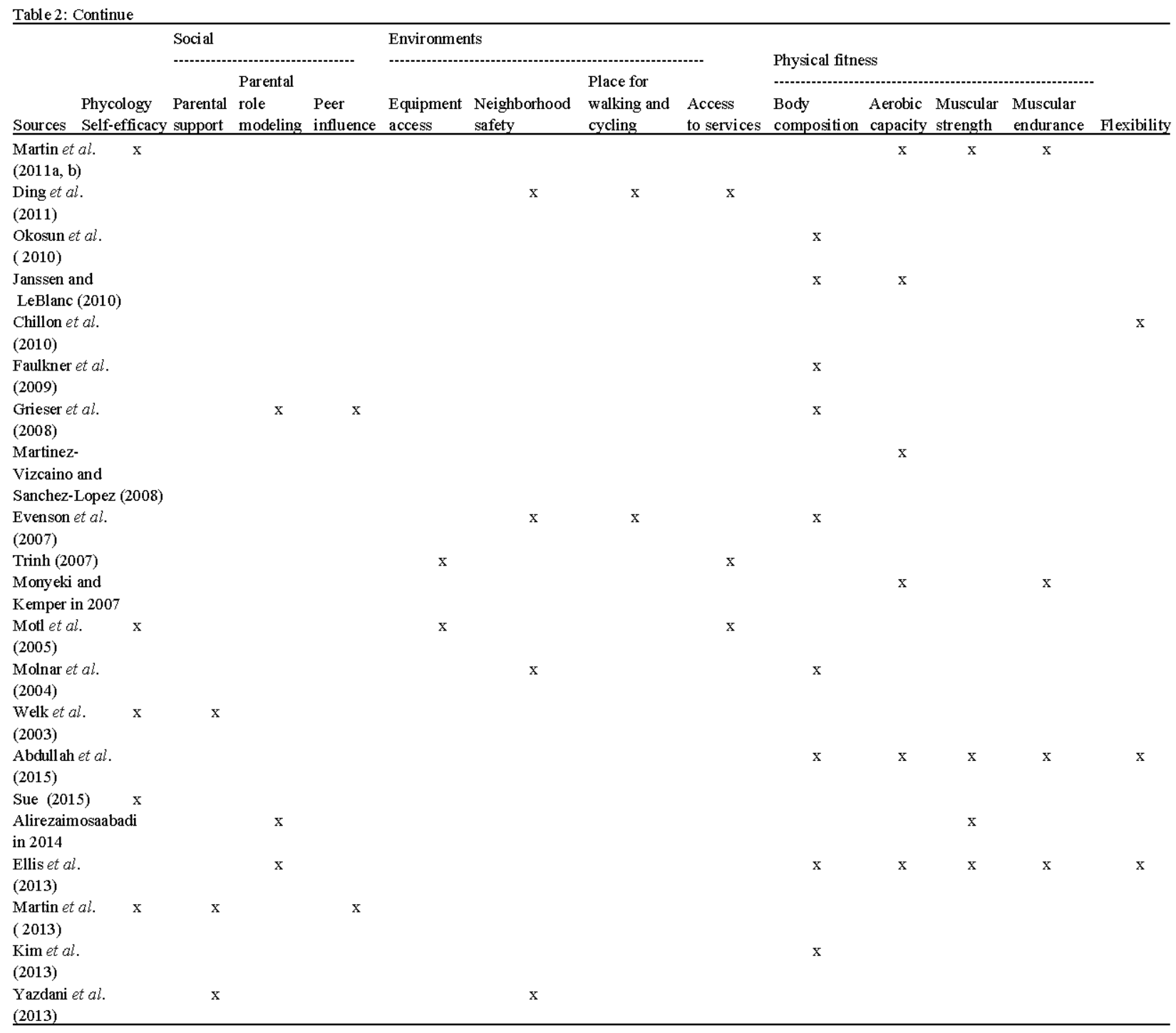

fitness domain were have deduced a number of factors that could have an influence on PA. These factors include body composition, aerobic fitness, muscular strength, muscular endurance and flexibility and all these factors play importance roles to increase PA level among children and adolescents with D/HI.

In the social domain, we found that parental support, parental role modeling and peer support are key factors in physical activity among children and adolescents with hearing impairments. The environmental domain has an effect on physical activity where the availability of suitable environments could encourage them toward engagement in PA. In the environmental domain four factors were to have an effect on PA. These factors are equipment access, neighborhood safety, places for walking and cycling and access to services. All these factors play key roles in physical activity among children and adolescents with $\mathrm{D} / \mathrm{HI}$.
The psychological domain found that the selfefficacy factor has an influence on the children's and adolescents' PA. A number of studies (Cozett, 2014; Garcia et al., 2016) have reported that self-efficacy factor is most strongly associated with children and adolescents MVPA. Individuals with high self-efficacy tend to have higher PA, especially those who perceived social support from peers or family.

The researchers found that physical fitness, social, environmental and psychological factors have an effect on PA of children and adolescents with $\mathrm{D} / \mathrm{HI}$, making them more physically active. As evidenced in the previous literature, there are few researches on PA among children and adolescents with D/HI. This study focused on the PA among children and adolescents who are $\mathrm{D} / \mathrm{HI}$. The literature review was made based on the information needed for children and adolescents who are D/HI. The significance of this study is in the in-depth understanding 


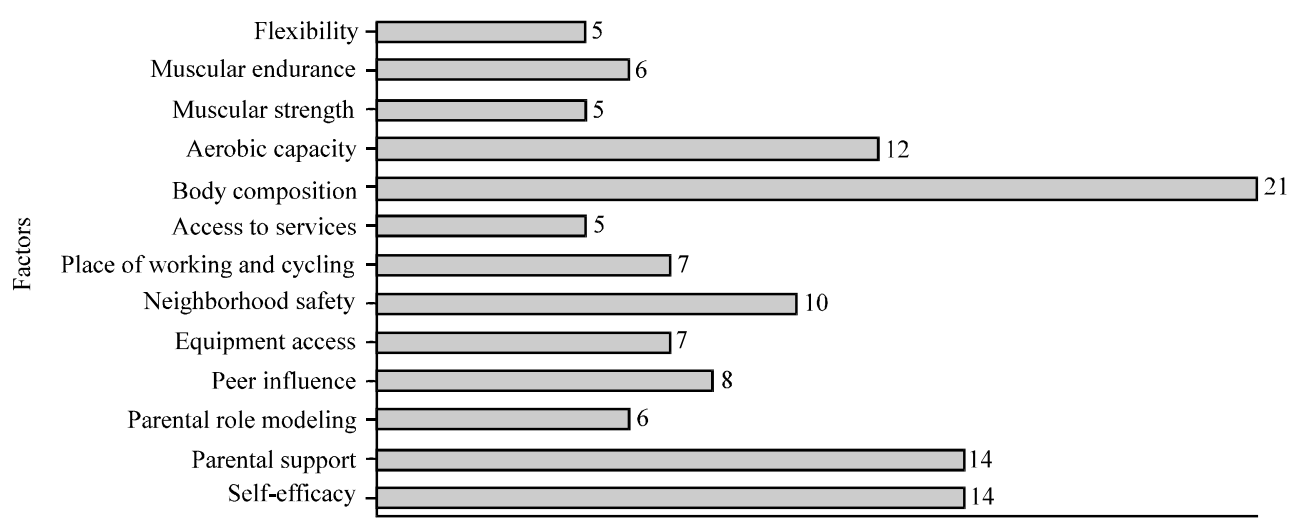

Fig. 1: Critical success factors most frequently found

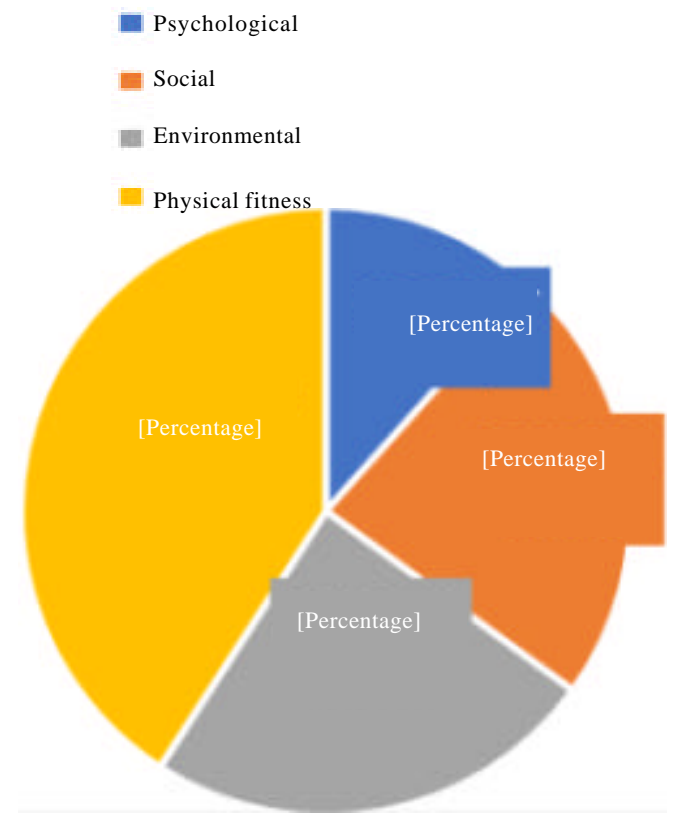

Fig. 2: Distribution of articles according to domain

of the key factors that could have an effect on children and adolescents in their PA. Furthermore, it addressed the current needs and issues to enhance their physical activity and prevent health risk when they are inactive.

As we can see, the majority of the researches focuses on as body composition, parental support and self-efficacy factor while some factors have low frequency as shown in Fig. 1. Therefore, it is recommended to focus on the rarely considered factors in this research area in order to ensure a successful implemented higher physical activity in their children.

When viewing the distribution of articles based on various domains (Fig. 2), it is obvious that most of these studies concentrated on the physical fitness domain
(41\%). Of these, the bulk of them highlighted physical fitness while the rest paid attention to body composition, aerobic capacity, muscular endurance, muscular strength and flexibility. Furthermore, environmental (24\%), social $(24 \%)$, psychological $(12 \%)$ are all domains where more than one study was conducted. Therefore, there is a need to focus on the psychological part to increase selfefficacy in order to be more active (Table 2).

\section{CONCLUSION}

This study was carried out to determine and examine the most common predictive factors for PA among children and adolescents with $\mathrm{D} / \mathrm{HI}$.

\section{SUGGESTIONS}

The researchers suggest the combination between physical fitness, social, environmental domain because these comprise factors that could help the $\mathrm{D} / \mathrm{HI}$ children psychologically. Increase the self-efficacy could also increase their capability to participate in an activity. This combination between domains and factors has not been considered in the literature. The researchers recommend that future studies should be carried out to investigate these factors in depth and empirically.

\section{REFERENCES}

Abdullah, N.M., V. Parnabas, M.S. Omar-Fauzee and M.N. Nazaruddin, 2014. Using field tests for predicting the general physical fitness level of students with hearing-impaired. Intl. J. Phys. Social Sci., 4: 356-368.

Ahmed, F., H. Zainuddin and S. Zahraa, 2016. Barriers of adopting E-learning in developing countries. J. Eng. Appl. Sci., 11: 2815-2820. 
Artero, E.G., V. Espana-Romero, F.B. Ortega, D. Jimenez-Pavon and J.R. Ruiz et al., 2010. Health-related fitness in adolescents: Underweight and not only overweight, as an influencing factor. The AVENA study. Scand. J. Med. Sci. Sports, 20: 418-427.

Baskin, M.L., A. Dulin-Keita, H. Thind and E. Godsey, 2015. Social and cultural environment factors influencing physical activity among AfricanAmerican adolescents. J. Adolescent Health, 56: 536-542.

Bianco, A., M. Jemni, E. Thomas, A. Patti and A. Paoli et al., 2015. A systematic review to determine reliability and usefulness of the field-based test batteries for the assessment of physical fitness in adolescents-The ASSO project. Int. J. Occup. Med. Environ. Health, 28: 445-478.

Bult, M.K., O. Verschuren, M.J. Jongmans, E. Lindeman and M. Ketelaar, 2011. What influences participation in leisure activities of children and youth with physical disabilities? A systematic review. Res. Dev. Disabil., 32: 1521-1529.

Button, B.L.G., 2013. Is the association between the built environment at school and students physical activity moderated by the social environment?. Master Thesis, Queen's University, Kingston, Ontario, Canada.

Campbell, N.J., 2012. The measurement of physical activity and self-efficacy in adolescents: Prospects, problems and future directions. Master Thesis, University of Western Ontario London, Ontario.

Chillon, P., J. Castro-Pinero, J.R. Ruiz, V.M. Soto and A. Carbonell-Baeza et al., 2010. Hip flexibility is the main determinant of the back-saver sit-and-reach test in adolescents. J. Sports Sci., 28: 641-648.

Cozett, C., 2014. Factors influencing particpation in physical activity in 11-13 year-old primary school children in the Western Cape. Master Thesis, University of Western Cape, Cape Town, South Africa.

Ding, D., J.F. Sallis, J. Kerr, S. Lee and D.E. Rosenberg, 2011. Neighborhood environment and physical activity among youth: A review. Am. J. Preventive Med., 41: 442-455.

Echeverria, E., 2014. Physical activity, physical fitness, body composition and academic performance in children and adolescents. Ph.D Thesis, Autonomous University of Madrid, Madrid, Spain.

Ellis, M.K., L. J. Lieberman and G.M. Dummer, 2013. Parent influences on physical activity participation and physical fitness of deaf children. J. Deaf Stud. Educ., 19: $270-281$.
Evenson, K.R., M.M. Scott, D.A. Cohen and C.C. Voorhees, 2007. Girls' perception of neighborhood factors on physical activity, sedentary behavior and BMI. Obesity, 15: 430-445.

Farias-Junior, J.C.D., A.D. Silva-Lopes, J. Mota, M.P. Santos and J.C. Ribeiro et al., 2011. Perception of the social and built environment and physical activity among Northeastern Brazil adolescents. Preventive Med., 52: 114-119.

Faulkner, G.E., R.N. Buliung, P.K. Flora and C. Fusco, 2009. Active school transport, physical activity levels and body weight of children and youth: A systematic review. Preventive Med., 48: 3-8.

Garcia, J.M., J.R. Sirard, R. Larsen, M. Bruening and M. Wall et al., 2016. Social and psychological factors associated with adolescent physical activity. J. Phys. Act. Health, 13: 957-963.

Grieser, M., D. Neumark-Sztainer, B.I. Saksvig, J.S. Lee and G.M. Felton et al., 2008. Black, Hispanic and white girls perceptions of environmental and social support and enjoyment of physical activity. J. Sch. Health, 78: 314-320.

Hartman, E., C. Visscher and S. Houwen, 2007. The effect of age on physical fitness of deaf elementary school children. Pediatr. Exercise Sci., 19: 267-278.

Hinckson, E.A., S. Duncan, M. Oliver, S. Mavoa and E. Cerin et al., 2014. Built environment and physical activity in New Zealand adolescents: A protocol for a cross-sectional study. BMJ. Open, 4: 1-11.

Huang, Y.J., S.H. Wong, J. Salmon and S.S. Hui, 2011. Reliability and validity of psychosocial and environmental correlates measures of physical activity and screen-based behaviors among Chinese children in Hong Kong. Intl. J. Behav. Nutr. Phys. Act., 8: 1-16.

Janssen, I. and A.G. LeBlanc, 2010. Systematic review of the health benefits of physical activity and fitness in school-aged children and youth. Intl. J. Behav. Nutr. Phys. Act., 7: 40-56.

Jiying, L., 2013. Psychosocial and environmental determinants of physical activity in elementary school children: Implications for interventions to reduce childhood. Ph.D Thesis, University of Louisville, Louisville, Kentucky.

Kadhum, A.M. and M.K. Hasan, 2017. Assessing the determinants of cloud computing services for utilizing health information systems: A case study. Intl. J. Adv. Sci. Eng. Inf. Technol., 7: 503-510.

Kim, Y., R.T. Conners, P.D. Hart, Y.S. Kang and M. Kang, 2013. Association of physical activity and body mass index with metabolic syndrome among US adolescents with disabilities. Disability Health J., 6: 253-259. 
Kurkova, P., 2016. Physical activity among older people who are deaf and hard of hearing: Perceived barriers and facilitators. Phys. Act. Rev., 4: 72-80.

Larouche, R., T.J. Saunders, G.E.J. Faulkner, R. Colley and M. Tremblay, 2014. Associations between active school transport and physical activity, body composition and cardiovascular fitness: A systematic review of 68 studies. J. Phys. Act. Health, 11: 206-227.

Leily, A., S. Esmail and N. Tahmores, 2014. Relation between physical activity and social adaptability in intermediate deaf students in southeast provinces of country. Intl. J. Sport Stud., 4: 126-132.

Liang, Y., P.W. Lau, W.Y. Huang, R. Maddison and T. Baranowski, 2014. Validity and reliability of questionnaires measuring physical activity self-efficacy, enjoyment, social support among Hong Kong Chinese children. Preventive Med. Rep., 1: 48-52.

Martin, J.J., D.R. Shapiro and E. Prokesova, 2013. Predictors of physical activity among Czech and American children with hearing impairment. Eur. J. Adapted Phys. Act., 6: 38-47.

Martin, J.J., N. McCaughtry, A.S. Murphy, S. Flory and K. Wisdom, 2011a. Psychosocial aspects of physical activity and fitness in special-population, minority middle school children. Eur. J. Adapted Phys. Act., 4: 54-68.

Martin, J.J., N. McCaughtry, S. Flory, A. Murphy and $\mathrm{K}$. Wisdom, 2011b. Using social cognitive theory to predict physical activity and fitness in underserved middle school children. Res. Q. Exercise Sport, 82: 247-255.

Martinez-Vizcaino, V. and M. Sanchez-Lopez, 2008. Relationship between physical activity and physical fitness in children and adolescents. Spanish J. Cardiol., 61: 108-111.

McNamee, J., G.L. Timken, S.C. Coste, T.L. Tompkins and J. Peterson, 2016. Adolescent girls physical activity, fitness and psychological well-being during a health club physical education approach. Eur. Phys. Educ. Rev., 23: 517-533.

Molnar, B.E., S.L. Gortmaker, F.C. Bull and S.L. Buka, 2004. Unsafe to play? Neighborhood disorder and lack of safety predict reduced physical activity among urban children and adolescents. Am. J. Health Promotion, 18: 378-386.

Motl, R.W., R.K. Dishman, D.S. Ward, R.P. Saunders and M. Dowda et al., 2005. Perceived physical environment and physical activity across one year among adolescent girls: Self-efficacy as a possible mediator? J. Adolesc. Health, 37: 403-408.
Nicolas, M.O., M.P. James, I.R. Alyssa, J.L. Joseph and B.J. Chen et al., 2015. Adolescents use of the built environment for physical activity. BMC. Publ. Health, 15: 251-259.

Okosun, I.S., J.M. Boltri, R. Lyn and M. Davis-Smith, 2010. Continuous metabolic syndrome risk score, body mass index percentile and leisure time physical activity in American children. J. Clin. Hypertens, 12: 636-644.

Richard, P.H., 2015. Parental influence on the physical activity behavior of school-age children in a socio-economically diverse community. Ph.D Thesis, George Mason University, Fairfax, Virginia.

Sallis, J.F., R.B. Cervero, W. Ascher, K.A. Henderson and M.K. Kraft et al., 2006. An ecological approach to creating active living communities. Annu. Rev. Publ. Health, 27: 297-322.

Sampasa-Kanyinga, H., H.A. Hamilton, J. Willmore and J.P. Chaput, 2017. Perceptions and attitudes about body weight and adherence to the physical activity recommendation among adolescents: The moderating role of body mass index. Public Health, 146: 75-83.

Sarah, C., 2011. An examination of physical activity participation, sedentary behaviour, health, correlates of physical activity and physical activity enjoyment among Irish adolescents. Ph.D Thesis, Dublin City University, Dublin, Republic of Ireland.

Spratt-O'Shea, N., 2014. Validation and measurement of physical activity, sedentary behaviour and active travel in second level students using self-report and accelerometry. Ph.D Thesis, Waterford Institute of Technology, Waterford, Republic of Ireland.

Stewart, T., S. Duncan and J. Schipperijn, 2017. Adolescents who engage in active school transport are also more active in other contexts: A space-time investigation. Health Place, 43: 25-32.

Sue, B.B., 2015. An application of the transtheoretical model to physical activity. Adapted Phys. Act. Q., 3: 156-156.

Toriola, O.O., 2013. Health-related physical fitness, physical activity and body composition status of adolescent learners residing within the Tlokwe Municipality: PAHL study. Ph.D Thesis, North-West University, Potchefstroom, South Africa.

Trinh, L., 2007. The relationship between social support and adherence to a peer-based physical activity program among adolescent girls: A pilot study. Ph.D Thesis, University of Victoria, Victoria, British Columbia. 
Vancampfort, D., M. Probst, A. Daenen, T.V. Damme and M.D. Hert et al., 2016. Impact of antipsychotic medication on physical activity and physical fitness in adolescents: An exploratory study. Psychiatry Res., 242: 192-197.

WHO., 2013. Physical inactivity: A global public health problem. World Health Organization, Lahore, Pakistan.

WHO., 2014. Promoting physical activity in the Eastern Mediterranean Region through a life-course approach. World Health Organization, Lahore, Pakistan.

Welk, G.J., K. Wood and G. Morss, 2003. Parental influences on physical activity in children: An exploration of potential mechanisms. Pediatr. Exerc. Sci., 15: 19-33.
West, S.T., K.A. Shores and L.M. Mudd, 2012. Association of available parkland, physical activity and overweight in America's largest cities. J. Pub. Health Manage. Pract., 18: 423-430.

Wilson, D.K., H.G. Lawman, M. Segal and S. Chappell, 2011. Neighborhood and parental supports for physical activity in minority adolescents. Am. J. Preventive Med., 41: 399-406.

Xu, F., E. Leslie, Z. Wang, H. Zhou and N. Owen, 2016. Test-retest reliability of the physical activity neighborhood environment scale among school students in China. Public Health, 130: 91-94.

Yazdani, S., C.T. Yee and P.J. Chung, 2013. Peer reviewed: Factors predicting physical activity among children with special needs. Preventing Chron. Dis., 10: 1-8. 